\title{
Incidence of Bacteremia at the Time of ICU Admission and its Impact on Outcome
}

\author{
Jose B Cherayath ${ }^{1}$, Jitin George ${ }^{2}$ \\ ${ }^{1}$ Associate Professor, Department of Anaesthesia, P K Das Medical College, Vaniyamkulam, Ottapalam, Palakkad, Kerala-679522, India, ${ }^{2}$ Assistant \\ Professor, Department of Anaesthesia, P K Das Medical College, Vaniyamkulam, Ottapalam, Palakkad, Kerala-679522, India.
}

\section{Abstract}

Background: For patients admitted in ICU, if they are suspected with infection, at admission time, blood culture is taken. Aim: This study aimed to evaluate the bacteraemia incidence at the ICU admission time, and assess its impact on the outcome. Subjects and Methods: This is a retrospective study which was conducted in a tertiary hospital. At time of admission, data from all the ICU admissions with suspected sepsis were analysed over a period of July 2016 to June 2018. The positive blood culture group (Group A) consisted of patients with clinically significant BSI. Results: 600 patients were selected in the study. 250 patients out of 600 patients (42\%) were on antibiotics. 380 patients out of 600 patients $(63 \%)$ were direct ICU admission from casualty, 70 patients from hospital wards (11\%), 45 patients from other ICU's in the hospital (8\%) and 105 patients from other hospitals (18\%). Blood cultures were positive only in 70 patients (11.6\%) with significant BSI. ICU mortality was significantly higher in positive blood culture group (i.e. 30/70), when compared with negative blood culture group (i.e. 68/530). Mortality was higher in patients with pseudomonas aeruginosa (75\%) though it was not statistically significant. Conclusion: In the ICU, only in minority of patients with suspected infection, blood cultures may be positive. Even though the patients are administered with antibiotics, prognosis of the patients with positive blood culture is worse.

Keywords: ICU admission bacteraemia, Sepsis.

Corresponding Author: Dr. Jitin George, Assistant Professor, Department of Anaesthesia, P K Das Medical College, Vaniyamkulam, Ottapalam, Palakkad, Kerala-679522, India.

Email: jitingorge989@gmail.com

Received: February 2020

Accepted: February 2020

\section{Introduction}

In critically ill patients, blood stream infection (BSI) is a severe life threatening condition. The increased use of invasive devices and immunosuppressive therapy has led to higher BSI incidence in patients admitted to intensive care units (ICU). In the ICU, nosocomial BSI has been considered to be the most frequently encountered infection. In the ICU, of all the ICU admissions, community acquired BSI accounts to $20 \%$ and $28 \%$ of all the BSI. ${ }^{[1]}$ BSI has been associated with increased treatment costs, length of stay, increased incidence and mortality. BSI causes $35 \%$ mortality and case fatality rate from bacteremic sepsis causing organ dysfunction ranges from $30 \%$ to $50 \% .^{[2]}$ The important factors which influence the patients outcome admitted to ICU with BSI are delay in treatment and inappropriate antimicrobial treatment. ${ }^{[3]}$ This is true for patients with severe sepsis or septic shock. Various studies were carried out to assess the implications and risk factors for nosocomial BSI and other factors and they have shown to predict independently mortality. However, at the time of ICU admission, there is a lack of data regarding implications and risk factors for BSI. Hence, this study aimed to evaluate the bacteraemia incidence at the ICU admission time, and assess its impact on the outcome and analyse risk factors that are related to poorer outcomes.

\section{Subjects and Methods}

This is a retrospective study which was conducted in a tertiary hospital. At time of admission, data from all the ICU admissions with suspected sepsis were analysed over a period of July 2016 to June 2018. Depending on the positivity of the blood cultures, the patients were divided into two groups. The positive blood culture group (Group A) consisted of patients with clinically significant BSI. The inclusion criteria was if a pathogenic organism was cultured from at least one set of blood cultures, it was deemed to be clinically significant BSI. To diagnose a BSI with common skin contaminants which includes coagulase negative staphylococci or bacillus, corynebacterium or propionibacterium species, and the patient with at least one of the signs and symptoms of sepsis, at least two positive sets of blood cultures were required and within 24 hour of a positive blood culture should be collected. The exclusion criteria was the patients who had incomplete medical records in terms of previous antibiotics usage and at admission, whose blood cultures were not sent. The blood cultures 
which did not fit the above mentioned clinical significant BSI definition. The demographics, source of infection, previous antibiotics, ICU course and microbiology report of positive blood culture were recorded. The Acute Physiology and Chronic Health Evaluation (APACHE) score was used to assess the severity of illness on admission. SPSS 14 version was used to analyse statistically. Chi square test or Fischer exact tests were used to analyse qualitative data and Students t-test was used to analyse quantitative data.

\section{Results}

600 patients were selected in the study. 250 patients out of 600 patients $(42 \%)$ were on antibiotics. 380 patients out of 600 patients $(63 \%)$ were direct ICU admission from casualty, 70 patients from hospital wards (11\%), 45 patients from other ICU's in the hospital $(8 \%)$ and 105 patients from other hospitals $(18 \%)$. Blood cultures were positive only in 70 patients $(11.6 \%)$ with significant BSI.

Table 1: Comparison of patient characteristics and ICU course according to blood culture positivity.

\begin{tabular}{|l|l|l|l|l|}
\hline Characteristics & $\begin{array}{l}\text { Overall } \\
(\mathbf{n = 6 0 0})\end{array}$ & $\begin{array}{l}\text { Group A } \\
(\mathbf{n = 7 0 )}\end{array}$ & $\begin{array}{l}\text { Group B } \\
(\mathbf{n = 5 3 0})\end{array}$ & $\begin{array}{l}\text { P } \\
\text { value }\end{array}$ \\
\hline Sex, Males (\%) & $\begin{array}{l}330 \\
(55 \%)\end{array}$ & $40(6.6 \%)$ & $290(48.3 \%)$ & 0.141 \\
\hline $\begin{array}{l}\text { Mean age, } \\
\text { years } \pm \text { SD }\end{array}$ & $60.6 \pm 9.7$ & $60.8 \pm 17.8$ & $60.3 \pm 18.7$ & 0.965 \\
\hline APACHE II score & $16.8 \pm 8.7$ & $17 \pm 9.4$ & $16.1 \pm 8.6$ & 0.172 \\
\hline $\begin{array}{l}\text { Previous } \\
\text { Antibiotics }\end{array}$ & 240 & 50 & 190 & 0.000 \\
\hline Inotropic Support & 160 & 34 & 126 & 0.000 \\
\hline Renal support & 90 & 20 & 70 & 0.000 \\
\hline $\begin{array}{l}\text { Mechanical } \\
\text { Ventilation }\end{array}$ & 165 & 35 & 130 & 0.000 \\
\hline $\begin{array}{l}\text { ICU stay, } \\
\text { days( } \pm \text { SD) }\end{array}$ & $5.6 \pm 6.7$ & $5.14 \pm 7.8$ & $5.6 \pm 6.8$ & 0.741 \\
\hline Mortality & 98 & 30 & 68 & 0.000 \\
\hline
\end{tabular}

[Table 1] shows that the ICU mortality was significantly higher in positive blood culture group (i.e. 30/70), when compared with negative blood culture group (i.e. 68/530). The risk factors for ICU mortality among bacteraemia patients was performed using univariate analysis, in which age $(p=0.965)$, sex $(p=0.141)$. APACHE II score $(p=0.172)$, ICU stay $(\mathrm{p}=0.741)$ and only previous antibiotic use was statistically associated with higher mortality $(\mathrm{p}=0.012)$.

Table 2: ICU mortality according to organism isolated in patients with positive blood cultures.

\begin{tabular}{|l|l|l|}
\hline Organism & $\begin{array}{l}\text { Number of patients } \\
(\mathbf{n = 7 0 ) , \%}\end{array}$ & ICU mortality (\%) \\
\hline Escherichia Coli & $30,43 \%$ & $14(47 \%)$ \\
\hline $\begin{array}{l}\text { Pseudomonas } \\
\text { aeroginosa }\end{array}$ & $12,17.1 \%$ & $9(75 \%)$ \\
\hline Kiebsiella Pneumoniae & $8,11.4 \%$ & $2(25 \%)$ \\
\hline Staphylococcus aureus & $6,8.6 \%$ & $3(50 \%)$ \\
\hline Others & $14,20 \%$ & $5(35.7 \%)$ \\
\hline Overall & 70 & $33(47.1 \%)$ \\
\hline
\end{tabular}

[Table 2] shows that mortality was higher in patients with pseudomonas aeruginosa $(75 \%)$ though it was not statistically significant.
From the patients who were admitted in ICU with suspected infection, blood cultures were taken routinely. The reported incidence of positive blood culture with BSI in patients admitted to ICU's is low $(3.2 \%$ to $4.3 \%)$. In the present study, the incidence of positive blood cultures which was taken from the time of admission to the ICU was $10.5 \%$. In critical care setting, bacteraemia sepsis is associated with high morbidity and mortality. It was found that ICU mortality was significantly higher in positive blood culture group (i.e. 43\%), when compared with negative blood culture group (i.e. 13\%). As there was increased need for organ support in bacteraemia patients, hence increased incidence of organ failure was observed. When compared to the crude mortality rate reported of $31.5-82.4 \%$, the present study showed a mortality rate of $43 \%$ in patients with BSI which was well within the range. ${ }^{[4-7]}$ In patients with BSI, there are various factors which influence the outcome such as type or source of bacteraemia and place of acquisition (community versus nosocomial). ${ }^{[7,8]}$ Higher mortality rates were associated with secondary bacteraemia when compared to primary bacteraemia. ${ }^{[7]}$ Various studies have reported significantly higher mortality rates in hospital acquired BSI when compared to community acquired BSI. ${ }^{[8-10]}$ A study done by Freidman ND observed patients with higher mortality rates in health care associated (29\%) and hospital acquired BSI (37\%) when compared to community acquired BSI $(16 \%) .{ }^{[8]}$ In various other studies, irrespective of severity of illness at the time of admission in ICU, higher mortality was observed in bacteraemia patients, when assessed by APACHE II score whereas in our study, increase in mortality three fold was observed in bacteraemia patients and there was no much difference statistically significance in APACHE II scores at admission between the two groups. ${ }^{[11]}$ This increased mortality observed with bacteraemia sepsis may be due to multiple organ dysfunction development, which is commonly observed in bacteraemia patients. Various other studies observed the risk of death after sepsis correlates with number of organ dysfunctions. ${ }^{[12,13]}$ It was observed in the present study that gram negative bacteraemia showed high incidence which was in accordance to subcontinent studies data, where as various studies conducted in western countries showed that higher incidence was observed of gram positive bacteraemia. It was found in the present study that number of patients affected higher were due to Escherichia Coli (43\%), followed by Pseudomonas aeruginosa $(17.1 \%)$ and Klebsiella Pneumonia $(11.4 \%)$. Increased mortality in patients was observed due to Pseudomonas which is in accordance with various other studies. $^{[14,15]}$ Small sample size can be the reason for increased mortality with pseudomonas not reaching statistical significance in our patients. It was observed that patients with positive blood cultures inspite of taking antibiotics had a significantly higher mortality rates. This could be due to inappropriate or under dosing antibiotics or due to infection with multidrug resistant organisms. Various other studies showed that for a better patient outcome, an early use of antibiotic therapy is a must. ${ }^{[16,17]}$

\section{Conclusion}


In the ICU, only in minority of patients with suspected infection, blood cultures may be positive. Even though the patients are administered with antibiotics, prognosis of the patients with positive blood culture is worse.

\section{References}

1. Van der Kooi TI, de Boer AS, Mannien J, Wille JC, Beaumont MT, Mooi BW, et al. Incidence and risk factors of device-associated infections and associated mortality at the intensive care in the Dutch surveillance system. Intensive Care Med. 2007;33:271-8.

2. Garrouste-Orgeas M, Timsit JF, Tafflet M, Misset B, Zahar JR, Soufir $\mathrm{L}$, et al. Excess risk of death from intensive care unit-acquired nosocomial bloodstream infections infections: A reappraisal. Clin Infect Dis. 2006;42:1118-26.

3. Blot SI, Depuydt P, Annemans L, Benoit D, Hoste E, De Waele JJ, et al Clinical and economic outcomes in critically ill patients with nosocomial catheter-related bloodstream infections. Clin Infect Dis. 2005;41:1591-8.

4. Rello J, Ricart M, Mirelis B, Quintana E, Gurgui M, Net A, et al. Nosocomial bacteremia in a medical-surgical intensive care unit: Epidemiologic characteristics and factors influencing mortality in 111 episodes. Intensive Care Med. 1994;20:94-8.

5. Smith RL, Meixler SM, Simberkoff MS. Excess mortality in critically ill patients with nosocomial bloodstream infections. Chest. 1991;100:164-7.

6. Forgacs IC, Eykyn SJ, Bradley RD. Serious infection in the intensive therapy unit: A 15-year study of bacteraemia. Q J Med. 1986;60:773-9.

7. Brun-Buisson C, Doyon F, Carlet J. Bacteremia and severe sepsis in adults: A multicenter prospective survey in ICUs and wards of 24 hospitals.French Bacteremia-Sepsis Study Group. Am J Respir Crit Care Med. 1996;154:617-24.
8. Friedman ND, Kaye KS, Stout JE, McGarry SA, Trivette SL, Briggs JP, et al. Health care-associated bloodstream infections in adults: A reason to change the accepted definition of community acquired infections. Ann Intern Med. 2002;137:791-7.

9. Shorr AF, Tabak YP, Killian AD, Gupta V, Liu LZ, Kollef MH Healthcare.associated bloodstream infection: A distinct entity? Insights from a large U.S. database. Crit Care Med. 2006;34:2588-95.

10. Vallés J, Calbo E, Anoro E, Fontanals D, Xercavins M, Espejo E, et al. Bloodstream infections in adults: Importance of healthcare-associated infections. J Infect. 2008;56:27-34.

11. Knaus WA, Draper EA, Wagner DP, Zimmerman JE. APACHE II: A severity of disease classification. Crit Care Med. 1985;13:818-29.

12. Hebert PC, Drummond AJ, Singer J, Bernard GR, Russell JA. A simple multiple system organ failure scoring system predicts mortality of patients who have sepsis syndrome. Chest. 1993;104:230-5.

13. Fagon JY, Chastre J, Novara A, Medioni P, Gibert C. Characterization of intensive care unit patients using a model based on the presence or absence of organ dysfunctions and/or infection: The ODIN model. Intensive Care Med. 1993;19:137-44.

14. Singhi S, Ray P, Mathew JL, Jayashree M, Dhanalakshmi Nosocomial bloodstream infection in a pediatric intensive care unit. Indian J Pediatr. 2008; 75:25-30.

15. Bhat S, Fujitani S, Potoski BA, Capitano B, Linden PK, Shutt K, et al. Pseudomonas aeruginosa infections in the Intensive Care Unit: Can the adequacy of empirical beta-lactam antibiotic therapy be improved? Int J Antimicrob Agents. 2007;30:458-62.

16. Madia MMH, Singh AK, Richi SMW, Singh RB. A Comparison of Perioperative Hemodynamic Stability with Amlodipine and Telmisartan during Laparoscopic Cholecystectomy in known Hypertensive Patients. Asian J. Med. Res. 2019;8(2):AN04-AN07..

17. Ibrahim EH, Sherman G, Ward S, Fraser VJ, Kollef MH. The influence of inadequate antimicrobial treatment of bloodstream infections on patient outcomes in the ICU setting. Chest. 2000;118:146-55.

Copyright: (C) the author(s), 2020. It is an open-access article distributed under the terms of the Creative Commons Attribution License (CC BY 4.0), which permits authors to retain ownership of the copyright for their content, and allow anyone to download, reuse, reprint, modify, distribute and/or copy the content as long as the original authors and source are cited.

How to cite this article: Cherayath JB, George J. Incidence of Bacteremia at the Time of ICU Admission and its Impact on Outcome. Acad. Anesthesiol. Int. 2020;5(1):61-63.

DOI: dx.doi.org/10.21276/aan.2020.5.1.12

Source of Support: Nil, Conflict of Interest: None declared. 